\title{
Structural Assessment for Deteriorated Old Building Located in Bethlehem City, Palestine
}

\author{
Nafeth NaserAlddeen \\ College of Engineering, Palestine Polytechnic University, Palestine \\ Received February 26, 2020; Revised April 3, 2020; Accepted April 19, 2020
}

Copyright $\mathrm{C} 2020$ by authors, all rights reserved. Authors agree that this article remains permanently open access under the terms of the Creative Commons Attribution License 4.0 International License

\begin{abstract}
Structural assessment of existing old constructions under gravity loads has a high social and economic effect. In many countries around the world, most of the buildings date back to 1960s and 1970s and cannot ensure satisfactory seismic response, since many areas have been later classified as seismic or their design have been carried out according to obsolete codes. These structures are generally reinforced with smooth bars that exhibit poor bonds and need specific anchoring end details. In the present paper, some key aspects of structural models of old-type masonry building analysis are reported. The paper consists of a general description of the building, the results of in-situ survey and inspection, field observation records, structural investigation, determination of the mechanical and physical properties of the used constructional materials. It will also include the engineering structural analyses, assessment of its performance for gravity and seismic loads. Finally, our findings and recommendations are regarding its structural performance, behavior under prevailing conditions, new loads applied resulting from additional new steel structure floor and remedial measures approaches to improve the structural system for resisting the applied loads. The structural analysis will be provided in a separate report.
\end{abstract}

Keywords Stone, Structural Assessment, Old Buildings, Inspection, Performance

\section{Introduction}

Studies nowadays are directed to the conservation and restoration of historical structures that have recourse to structural analysis as a way to better understand the genuine structural features of the building, to characterize its present condition and actual causes of existing damage, to determine the true structural safety for a variety of actions, gravity, soil settlements, wind and earthquake and to conclude on necessary remedial measures. In short, structural analysis contributes to all the phases and activities (including diagnosis, reliability assessment and design of intervention) oriented to grant an efficient and respectful conservation of monuments and historical buildings. Accurate structural analysis is needed to avoid erroneous or defective conclusions leading to either over-strengthen the structure, causing unnecessary loss in terms of original material and cultural value, or to insufficiently intervene on it, and hence generate inadmissible risks on people and heritage. Unsurprisingly, ancient structures have been studied, since long time ago, using the most advanced tools available for structural assessment.

The application of advanced computer methods to the analysis of historical structures was pioneered by the studies of the Brunelleschi Dome by Chiarugi et al. [1], the Pisa Tower by Macchi et al. [2], the Colosseo in Rome by Croci [3], also Croci and Viscovik [4], Mexico Cathedral by Meli and Sánchez-Ramírez [5] and San Marco's Basilica in Venice by Mola and Vitaliani [6], By then, the development of methods for accurate analysis of steel and concrete structures, including non-linear applications, was already at a very advanced stage thanks to the work of Zienkiewicz and Taylor [7], Ngo and Scordelis [8] and many others. Notwithstanding, analysts attempting to use computer tools for the study historical structures were by then facing overwhelming challenges. P. Roca et al. [9] tackled the specific problems of ancient constructions concerning materials, structural arrangements and real preservation condition. In fact, the difficulties posed by historical structures are still very challenging, and still reminiscent of those encountered by the pioneers, in spite of significant progress during the last decades. Some of difficulties encountered are related to the description of geometry, materials and actions, all of which acquire remarkable singularity in the case of historical construction. 
Additional important difficulties are related to the acquisition of data on material properties, internal morphology and damage, as well as to the adequate interpretation of structural arrangements, overall organization and historical facts. Because of all these difficulties, it is generally accepted (Icomos/Iscarsah Committee [10]) that the study of a historical structure should not only based on calculations, but should integrate as well a variety of complementary activities involving detailed historical investigation, deep inspection by means of nondestructive techniques (NDT) and monitoring, among other. Structural analysis of historical structures constitutes in fact a multidisciplinary, multifaceted activity requiring a clever integration of different approaches and sources of evidence. These difficulties are discussed in more detail in the following paragraphs.

This paper presents results of our inspection and structural evaluation carried out for Old building located in Bethlehem City, Palestine. Structural inspection of the old building components and site investigation was conducted in general accordance with the owner.

The purpose of this inspection report is to investigate the existing condition of the building and evaluate its structural elements for purposes of rehabilitation and improvement of its function and serviceability.

The report consists of a general description of the building, the results of in-situ survey and inspection, field observation records, structural investigation, determination of the mechanical and physical properties of the used constructional materials, engineering structural analyses and assessing its performance for gravity and seismic loads and finally our findings and recommendations regarding its structural performance and behavior under prevailing condition and new loads applied resulting from additional new steel structure floor and remedial measures approaches to improve the structural system for resisting the applied loads.

\section{Purpose and Challenges}

This paper aims to investigate the existing condition of the building and evaluate its structural elements and provide our findings and recommendations related to the building structural performance. Scope of our work included the followings:

1. Review of all available construction documents including the architectural drawings related to the original construction and future serviceability of the building.

2. Field visits to the building site and visual in-situ survey and observations records for the building components and elements under prevailing conditions.

3. Collecting data and information related to the use and future serviceability of the existing building.
4. On-Site investigation and geotechnical analysis to explore and identify the subsurface condition prevailing in the building site and characteristics.

5. Investigation and evaluating the general state and the structural system of the building to determine nature and type of the existing defects.

6. Field and laboratory tests conducted on representative samples obtained from the used construction materials including destructive and non-destructive testing.

7. Structural evaluation to identify the structural system and differentiate the findings associated with the needed improvement works and future performance of the building.

8. Preparing this report to document the purposes and scope of the inspection, methodology on-site investigation, field and laboratory testing results, findings and recommendations.

\section{Building Description}

The existing structure under investigation is an isolated Villa House building located in Bethlehem City. The main entrance gate is from the south frontispiece. Fence course masonry stone walls of height about $1.8 \mathrm{~m}$ surrounded the building from all sides. The building was originally used as a house building, but it had been changed being used recently as school building. According to a statement written on the entrance doorplate from west side, the building was constructed in year 1938. The plan drawings and sections are shown in Figures of Appendix A.

The building is a two floors structure with a roof floor consisting of small service rooms. Area of plan area of each floor is about $225 \mathrm{~m} 2$ and the total height of the two floors building is about $8.8 \mathrm{~m}$ and total height is $12.0 \mathrm{~m}$ including the roof floor structure. The building geometry is regular in shape and measures $16.54 \mathrm{~m}$ in length and $13.6 \mathrm{~m}$ in width in the perpendicular direction. The story height at the ground level varies between $2.7 \mathrm{~m}$ and $4.5-\mathrm{m}$ and this floor is partly under the ground level. The floor levels are arched vaults with a maximum clear height $4.7 \mathrm{~m}$ with vaulted opens for windows and doors. The two floors were connected with internal stone stair case. The roof of the building was covered by old traditional stone tiles of thickness $3-7 \mathrm{~cm}$. A cistern of pear shaped was dug below the entrance ground level and circular rock cut in the subsurface weak rocky layer about 8.5-m deep and $1.5 \mathrm{~m}$ in top diameter which increases with depth to about $2.5 \mathrm{~m}$ at the bottom.

The construction materials used in the building were course-stone units of limestone and infill consisting of rubble stone bind together with lime and clay mortar. Finishing and interior works for the building had been carried out and involved internal wall surfaces painting and masonry stone pointing works. Figures 1 shows the general view of the building. 


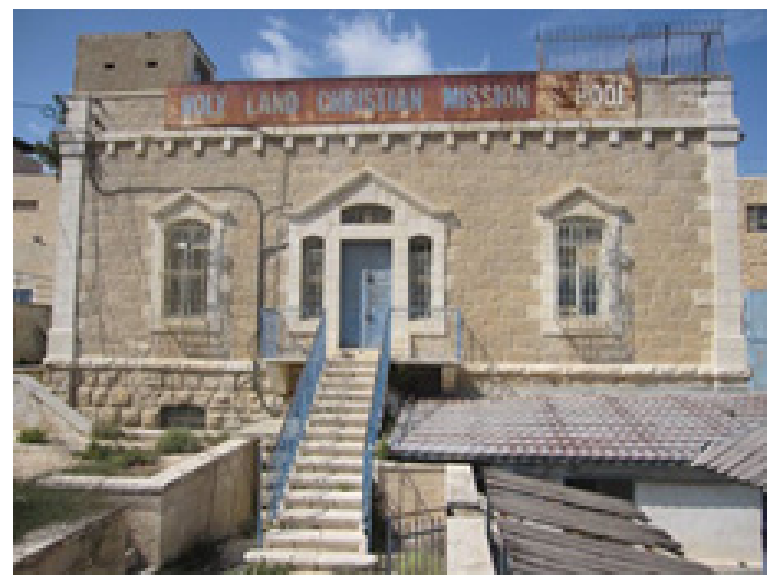

Figure 1. General view of the building -North West Facades

\section{On-Site Inpection and Investigation}

The whole building and all its structural components and elements were examined and inspected in details. Inspection was made best as possible where access was allowed for all structural elements. The in-situ survey and field observations were carried out and recorded during field visits conducted throughout March 18 to 26, 2018. The inspection results and observation records are summarized in the followings:

1. The overall stability of the structure is considered in good condition. The main structural problems are minor interior cracks appearing in the plastering mortars of varied width 1-3mm as shown in Figure 2. These cracks were limited to the plastering mortar layer. Some minor cracks appeared in the façade stone pointing groove lines mortar layer as a result of shrinkage and mortar dislodging.

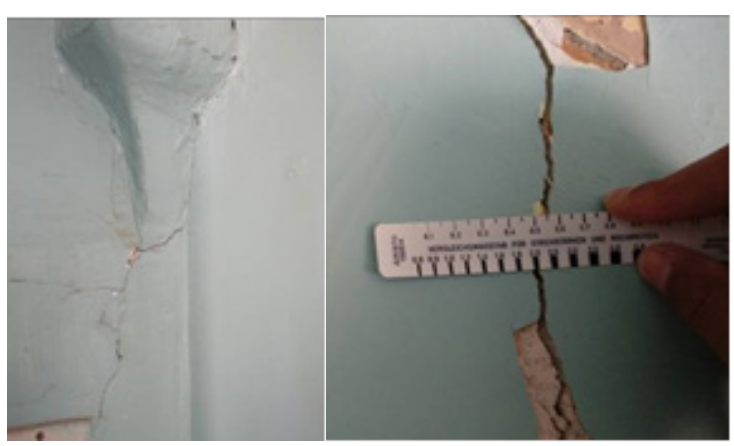

Figure 2. Cracks appeared in the internal plastering la

2. No major failure cracks or sign of any systematic structural failure were observed in all of the bearing elements of the inspected structure. Only minor cracks were observed in the arched opens and interior walls partitions and a narrow flexural crack occurred in the sill stone at a window open located in the western façade wall as shown in Figure 3.

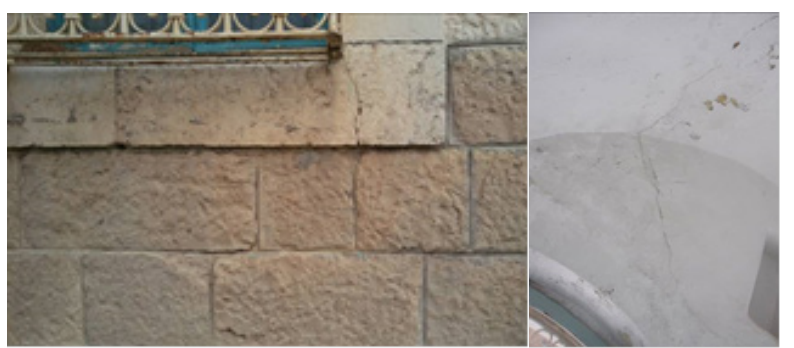

Figure 3. Cracks appeared in the arched opens and in the sill stone at western window open

3. The internal arched slab and wall surfaces were covered by low resistance lime-sand mortar of thickness varied between $2 \mathrm{~cm}$ and $4 \mathrm{~cm}$.

4. Bedding joints of the course stone units were filled with low lime -clay mortar. Width of the bedding stone horizontal and vertical joints varied between $15 \mathrm{~mm}$ and $25 \mathrm{~mm}$.

5. No maintenance and repairs works had been carried out for the whole building; the rehabilitation works included only painting the interior wall surface. Re pointing of the facing stone walls was carried out at some portion for façade walls. Pointing was carried out using Portland Cement-Sand mortar. Hand tools were used for raking the stone joints to a surface depth not exceeded $3-5 \mathrm{~mm}$. Concave tooling was used for marking pointing line and to provide water tightness of the joints. Loose joints due to deteriorated joints mortar were occurred particularly at the repaired joints. Low to moderate resistant lime mortars for plastering and pointing were used in the original construction materials which can be removed by hand tools.

6. A parapet wall of thickness $40-\mathrm{cm}$ and of height $0.65-\mathrm{m}$ was built above the first floor and roof line.

7. Strap of stone tiles of various sizes and shape was covered the exterior passages ground around the perimeter of the building. Stone tiles were placed directly over fill materials consisting of soft clay mixed with some gravels and cobbles.

8. Poor surface drainage gradient and plant waste accumulation at the western perimeter passage as shown in Figure 4 permitted pond of water and leaking into the subsurface soil and damping the backfilling soil behind the ground floor wall at the part located below the exterior on grade level.

9. Stone used in construction of the bearing walls were hand cut made from good quality limestone and mostly hard obtained from local queries and trimmed manually. Height of the stone courses was $38-43 \mathrm{~cm}$ for the ground floor façade wall with bedding width of the course stone varying from $15-20 \mathrm{~cm}$ and $24-$ $28 \mathrm{~cm}$ for windows opens threshold and lintel units (stone units for edges sides of the opens). For the first floor, the height of the course stone varied between 22 and $35 \mathrm{~cm}$ with bedding width about 
$15 \mathrm{~cm}$ and up to $28 \mathrm{~cm}$ for opens stone units. The façade stone was trimmed by hand tool of convex type for the ground floor and chisel trimming for the first floor and chisel fine trimming for the cut stones installed at building corners and opens convex projection along the face of the stone.

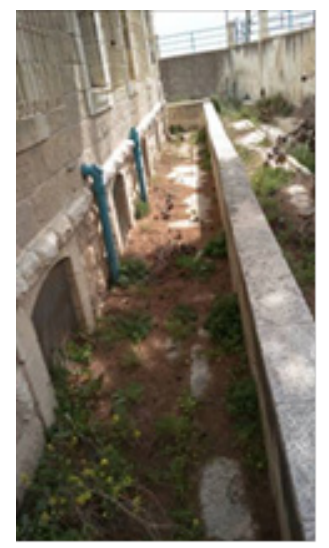

Figure 4. Ground surface condition at the west side

10. The total thickness of the stone-bearing wall was measured about $90-100 \mathrm{~cm}$ for the external walls and $45-80 \mathrm{~cm}$ for the internal walls (Plastering layer was inclusive). On top of the building, the roof-surrounding wall thickness of is $0.4-\mathrm{m}$

11. The Stone-bearing walls were constructed using two-leaves of coursed cut-stone and infill leaf consisted of rubble mixed with low resistant lime-clay mortar. Figure 5 shows cross section type of the walls as inspected in the building.

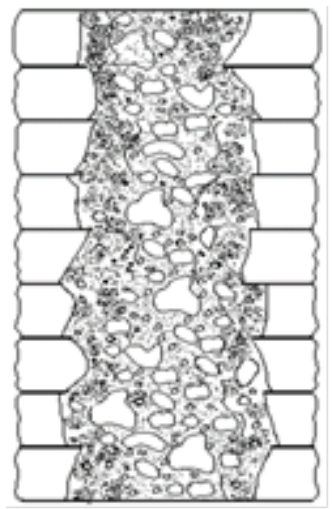

Figure 5. Cross-Section for the stone -bearing wall

12. The stone units of the staircase steps that connected between the ground level and first floor level were supported by two walls, whereas cantilevered stone units used in construction of the staircase steps connected the ground floor and the first floor levels.

13. Vaults structure was used to cover the ground and first levels spaces of different shapes. The vaults are bridging spans with dimensions equal to those of the rooms.

\section{Structural Condition}

The building was constructed using load-bearing walls and arch roof system. The load bearing elements (walls, piers and abutments) were built using two-leaves coursed cut-stone and infill composed of stone cobbles mixed with hydrated lime and clay mortars. Thickness of the interior stone-walls ranged between $45 \mathrm{~cm}$ and $80 \mathrm{~cm}$ and for the exterior wall $90 \mathrm{~cm}-100 \mathrm{~cm}$. The end support of the piers and abutments is of width wider than the wall width by

1. The structure system of the building is considered as load bearing stone-walls and corner abutments supporting the ceiling arched slabs. The structural system of the building is formed of the course stone walls and arch slabs. The stone walls width and abutment end support width forms the foundations of the building.

2. Ceiling arch slabs were built using matrix arch stones filled in between with lime clay mortar mixed with gravels and small cobles and covered by a smooth layer of lime mortar of thickness ranged between 2 and $3 \mathrm{~cm}$. The minimum thickness at the center of the shell arch slab was about $60 \mathrm{~cm}$.

3. The ceiling slab of the ground and first floors was covered by irregular stone tiles.

4. Internal partition walls were built using arched stone-wall system.

5. The exterior course stone-walls and the interior arch and abutments façade stones were of type medium hard to hard and generally appeared in good condition and of good quality laying.

6. Minor narrow local diagonal and vertical cracks occurred along scattered paths in the plastering layer. This may be caused due to the shrinkage influence and applied thick layer of fine plastering mortar. Width of cracks appearing was measured between $0.3 \mathrm{~mm}$ and $3.0 \mathrm{~mm}$

7. No major failure cracks or sign of any systematic structural failure were observed in all of the bearing elements of the inspected structural elements. Only minor cracks were observed in some of the arched opens and interior walls partitions.

8. No cracks as a result of footing settlement or soil deformation which affecting on the stability of the bearing structural elements were observed. Based on the general geology of the building area, the footings were laid on incompressible rocky layer consisting of weak marly marlstone.

9. Non buckling damage was observed in any of the structural supporting elements.

10. The main walls which are responsible for the horizontal resistance of the structure at the ground floor are shown in Figure 6 The colored walls continue over the height of the building, except the ones between the stairs. 


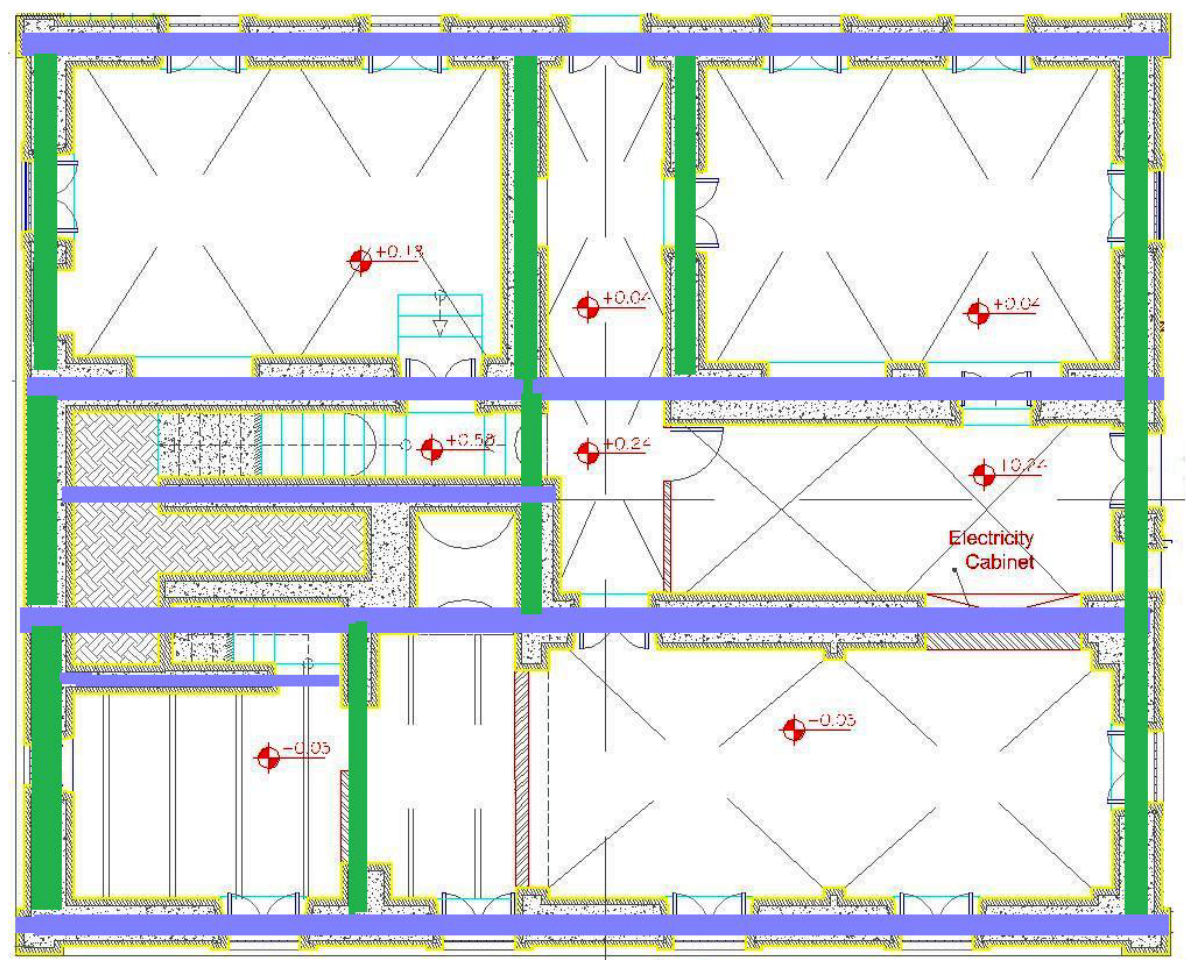

Figure 6. Load carrying structural walls (blue in $\mathrm{x}$ direction, green in $\mathrm{y}$-direction)

\section{Laboratory and Field Testing of the Construc- Tion Materials}

For the purpose of determining the physical and mechanical properties of the original materials used in co-construction of the structural components of the building, field and laboratory test were carried out on samples selected to be representative of the materials in-situ. The samples were obtained from different portions respecting to the building condition. Six bulk stone samples representative the stone used in construction of the building were selected and obtained. The bulk stones were sawed in laboratory to obtain specimens of size and dimensions adequate to carry out the required tests. For determining the compressive strength $60 \times 60 \times 60 \mathrm{~mm}$ cubes were tested in wet conditions by axial compression in accordance with ASTM C 170. The modulus of rupture was carried out on specimens approximately $100 \times 200 \times$ $50 \mathrm{~mm}$ in size. The test was carried out in the accordance with ASTM C 99. The modulus of elasticity was determined by the relationship between compressive stress and strain of prisms $50 \times 50 \times 100 \mathrm{~mm}$ prepared for each stone sample.

Compressive and shear strength tests were carried out on irregular samples of lime mortar samples obtained from lime mortars infill between the stone and cut into small nonstandard intact and sound cubes and prisms. Cubes specimens were prepared to produce specimens with two regular parallel sides as possible and cut to create approximate cube $35 \times 35 \times 35 \mathrm{~mm}$. The specimens for testing were cut dry by diamond circular saw. The cube specimens were tested in compression with the parallel surfaces placed between the loading plates. The strength was calculated as the maximum load was divided by the average area in the middle of the specimen. Samples extracted from lime mortar internal stone cover and internal joint were used to prepare circular specimens of dimensions suitable to carry out direct shear stress test according to ASTM C 3080.

The following laboratory and in situ tests were performed on the selected samples obtained from the used construction materials:

1. Compressive Strength of Dimension Stone, ASTM C170

2. Modulus of Rupture of Dimension Stone, ASTM C99

3. Rebound Number of Rock Using Schmidt Rebound Hammer, ASTM C 805

4. Absorption and Bulk Specific Gravity of Dimension Stone, ASTM C97

5. Specific Gravity of Soil, ASTM D 854-90

6. Liquid Limit, Plastic Limit, and Plasticity Index of Soils, ASTM D 4318-90

7. Direct Shear Test of Soils Under Consolidated Drained Conditions, ASTM C 3080

8. In situ Measurement of Masonry Mortar Joint Shear Strength Index, Method B, ASTM 1531

\subsection{Laboratory Testing Results the Construction Materials}

Results of laboratory and field testing carried out on stone and mortar materials are shown in Tables 1, 2 and 3. 
Table 1. Testing Results of the Stone Units

\begin{tabular}{|c|c|c|c|c|c|c|c|c|}
\hline \multirow{2}{*}{ Test } & & \multicolumn{6}{|c|}{ Sample No. } & \multirow{2}{*}{ Average } \\
\hline & & S1 & S2 & S3 & S4 & S5 & S6 & \\
\hline Specific Gravity & & 2.506 & 2.623 & 2.426 & 2.403 & 2.567 & 2.532 & 2.509 \\
\hline Absorption & $\%$ & 2.2 & 1.2 & 3.6 & 3.8 & 2.7 & 1.8 & 2.55 \\
\hline Compressive Strength,$f_{\text {unit }}$ & $\mathrm{MPa}$ & 46 & 74 & 32 & 27 & 59 & 53 & 48.5 \\
\hline Modulus of Rupture & $\mathrm{MPa}$ & 5.2 & 6.6 & 4.4 & 4.1 & 5.9 & 4.9 & 5.2 \\
\hline Modulus of Elasticity & $\mathrm{MPa}$ & 34500 & 59950 & 22400 & 17550 & 47800 & 45580 & 37963 \\
\hline Schmidt Hammer & $\mathrm{Ra}$ & 48 & 60 & 44 & 38 & 55 & 51 & 49 \\
\hline Stone Units Hardness & & \multicolumn{7}{|c|}{ Medium Hard to Hard } \\
\hline
\end{tabular}

Table 2. In-Situ Joint Shear Strength Index

\begin{tabular}{|c|c|c|}
\hline Test Location & & West Façade Wall- Window Edge Side First Floor \\
\hline Stone Unit Dimensions & $\mathrm{mm}$ & Width $250 \mathrm{~mm}$ and $600 \mathrm{~mm}$ Length \\
\hline Coefficient of friction for the Stone Unit & $\mu$ & 0.6 \\
\hline Bed Joint Shear Strength Index, $\tau$ & MPa & 0.39 \\
\hline $\begin{array}{l}\text { Reduced Bed Joint Shear Strength Index } \\
\text { Under Zero Axial Load } \tau_{0}\end{array}$ & $\mathrm{MPa}$ & 0.31 \\
\hline
\end{tabular}

Table 3. Testing Results of the Infill and Lime Mortars Materials

\begin{tabular}{|cc|c|c|c|c|c|c|c|}
\hline \multirow{2}{*}{ Test } & \multicolumn{7}{|c|}{ Sample No. } & \multirow{2}{*}{ Average } \\
\cline { 3 - 10 } & & $\mathrm{M} 1$ & $\mathrm{M} 2$ & $\mathrm{M} 3$ & $\mathrm{M} 4$ & $\mathrm{M} 5$ & M6 & 15.2 \\
\hline Dry Unit Weight & $\mathrm{KN} / \mathrm{m}^{3}$ & 15.3 & 14.4 & 15.8 & 15.3 & 16.1 & 14.1 & 0.45 \\
\hline Compressive Strength & $\mathrm{MPa}$ & 0.32 & 0.28 & 0.37 & 0.57 & 0.81 & 0.34 & 3.3 \\
\hline Strain at Maximum Stress & $\%$ & 3.1 & 2.8 & 3.5 & 3.6 & 3.8 & 3.2 & 24 \\
\hline Modulus of Elasticity & $\mathrm{MPa}$ & 14.2 & 13.2 & 16.2 & 26.5 & 37.2 & 36.7 & 34 \\
\hline Internal Friction Angle & $\mathrm{o}$ & 31 & 27 & 33 & 37 & 38 & 35 & 34 \\
\hline
\end{tabular}

\subsection{Characteristic Compression and Modulus of Elasticity of the Stone Wall}

Field inspection revealed that stones used in construction of the bearing facing walls were in good quality and mostly in hard condition and highly in strength. The characteristic strength of the stone wall may be calculated in accordance with EN 1996-1-1 Masonry Unreinforced Structures using the following equation:

$$
\mathrm{f}_{\text {sk }}=K \cdot \mathrm{f}_{\text {unit }}^{0.7} \cdot \mathrm{f}_{\text {mortar }}^{0.3}
$$

Where:

$f_{s k}$ : Characteristic Compressive Strength of the Masonry

$f_{\text {unit: }}$ Compressive Strength of the Stone Unit

$f_{\text {unit: }}$ Compressive Strength of the Mortar

$\mathrm{K}$ : Constant for Dimensional Stone

The modulus of elasticity may be determined according to the following equation:

$$
\mathrm{E}=\mathrm{KE}^{*} \mathrm{fk}
$$

Where:

fk: Characteristic Compressive Strength of the Masonry E: Modulus of Elasticity of the Stone Wall

KE: Constant $\approx 1000$

Based on results of tests carried out on stone units and mortar samples, values of the characteristic compression and modulus elasticity for the stone wall are determined and shown in the following Table 4

Table 4. Mechanical Parameters for the Wall Stone

\begin{tabular}{|c|c|c|}
\hline Characteristic Compressive Strength & $\mathrm{MPa}$ & 5.36 \\
\hline Modulus of Elasticity, E & $\mathrm{MPa}$ & $5360(4826)^{(1)}$ \\
\hline Shear Modulus, $G$ & $\mathrm{MPa}$ & $2144^{(2)}$ \\
\hline
\end{tabular}

(1) $\mathrm{E}=900 \mathrm{X}$ specified compressive strength of masonry $\left(f^{\prime}{ }_{m}\right)$, According to ACI 530.1-08 for concrete masonry

${ }^{(2)}$ The shear modulus, $\mathrm{G}$ taken as $40 \%$ of the elastic modulus, $\mathrm{E}_{\mathrm{m}}$. 


\section{Site Condition and Geotechnical Investiga- Tion}

\subsection{Site Topography}

The building site is located on atop of semi plain hilly area. The natural ground surface of the building site was gently sloping towards the south-east. The local drainage direction in the building site is from west to the east towards.

\subsection{Test Pits Excavation}

Footing inspection and the subsurface conditions at the site were explored by excavating three test pits inside the building within the ground floor area and at locations adjacent to stone wall and corner abutments to inspect and measure size and identify shape and condition of the existing foundation. Depth of the pits varies to follow the differences in the bottom of the foundation level. All of test pits depth reached the foundation level so the foundation depth could be recorded. The test pits were excavated to depths ranged between 1.2 to $2.0 \mathrm{~m}$ below the top level of the floor tile and about 0.30 below the footing depth level. The test pits were excavated to obtain samples as undisturbedly as possible and to record the condition and dimensions of the existing foundation.

\subsection{Soil Sampling and Testing}

The soil layer under the foundation was sampled and cored samples obtained from field bulk samples represent the bedrock footing layer using electrical core barrel machine. The test samples were cored and prepared in our lab. Laboratory tests were carried out on the selected soil samples in order to acquire necessary information with regards to the physical and mechanical properties of the bedrock layer found beneath the foundation and further to evaluate and determine the parameters required for the soil classification and strength. All phases of the laboratory-testing program were performed in general accordance with the latest version ASTM Standard Testing Methods. The following laboratory tests were conducted on the selected soil samples obtained from the rock formation underneath the footings:

\section{Visual classifications}

The samples returned to our laboratory were visually examined and classified in general accordance with ASTM D2487, Standard Practice for Classification of soils for Engineering Purposes Unified Classification System.

\section{Moisture Content}

The field moisture content as a percentage of dry weight of the soil was determined according to ASTM D
2216-03 and AASHTO T265-06 Standard Test Methods.

\section{Unconfined Compressive Strength}

Unconfined compression test was performed on cored samples prepared from rock undisturbed bulk sample. Test was carried out according to ASTM D 2938-08 Test Method.

\subsection{Results of Soil Laboratory Tests}

Results of tests are summarized in the following Table 5 .

Tables 5. Results of lab tests for the rock samples Test Pit No.

\begin{tabular}{|c|c|c|c|}
\hline Test Pit No. & & TP-1 & TP-2 \\
\hline Depth of Sampling & & 1.2 & 1.7 \\
\hline Moisture Content & $\%$ & 5.7 & 6.8 \\
\hline Dry Density, $(\gamma d)$ & $\mathrm{KPa}$ & 20.9 & 18.8 \\
\hline $\begin{array}{l}\text { Lab. Unconfined Compressive } \\
\text { Strength, } \mathrm{q}_{\mathrm{u}}\end{array}$ & $\mathrm{MPa}$ & 5.8 & 4.1 \\
\hline Drained Cohesion & $\mathrm{KPa}$ & 265 & 205 \\
\hline $\begin{array}{c}\text { Estimated Angle of Internal } \\
\text { Friction, } \Phi \\
\end{array}$ & & $38^{\circ}$ & $38^{\circ}$ \\
\hline Rock Quality Designation, RQD & \multicolumn{3}{|c|}{ Poor $25-40 \%$} \\
\hline Rock Classification & \multicolumn{3}{|c|}{$\begin{array}{c}\text { Slightly hard Marly Marlstone, } \\
\text { Poor RQD }\end{array}$} \\
\hline
\end{tabular}

\subsection{Geotechnical Inspection and Analysis}

The evaluation of the subsurface conditions were based on the inspection of the test pit excavations and observations of the deposits exposed on the site surface and the laboratory testing results carried out on representative samples.

\subsubsection{Subsurface Condition}

Field inspection of the test pits holes excavated revealed that the site was covered by about $0.5 \mathrm{~m}$ beige artificial fill material consisting of medium dense rock fragments of different sizes mixed with gravels and clayey soil. This backfill material can be classed as silty and clayey gravels of medium plasticity. Directly, below this near surface material, a thick layer of light beige slightly hard marly marlstone bedrock appeared. The bedrock layer was found slightly moist and in high compact condition (SPT of value $>50$ ). The bedrock layer can be described a weak to slightly hard and massive marly marlstone incompressible bedrock. The rock is composed mainly of marl and Marlstone.

The rock core recovery may ranges between 30-80\% and the RQD may ranges between $25-40 \%$ and classify poor rock quality. No karstic feature as a result of water dissolving the rock cavities created at shallow depths beneath the ground surface was observed. Accordingly, cavities and non-filled voids are absent in the building site. 


\subsubsection{Foundation Condition}

Footings of the piers and abutments were placed on the bedrock layer. The exterior stone walls located below facade opens and connected between the abutments and piers supports were not placed on bedrock but rested on leveling fill materials layer of thickness $40-50 \mathrm{~cm}$. The footing width of the abutments and piers was extended 15 $-20-\mathrm{cm}$ beyond the course stone units of the wall and abutment and built using stone units bonded together by low resistant lime mortar. Inspection of the embedded wall footings revealed that nonmajor cracks related to excess settlement occurred in all inspected below ground elements.

\subsubsection{Allowable Bearing Capac- Ity}

Based on the lab. testing results and strength parameters of the bedrock layer prevailed in the site the net allowable bearing pressure value applied to dead and live loads can be calculated by dividing the average compressive strength value of cored specimens with a reduction factor 15 , accordingly the calculated allowable bearing capacity is $390 \mathrm{KPa}$.Since the recommended bearing value is a net value, the weight of concrete may be taken as $18 \mathrm{KN} / \mathrm{m} 3$ and the backfill weight may be neglected when computing the imposed downward foundation load.

\section{Seismic Consideration}

Table 6. Seismic Site Coefficients

\begin{tabular}{|c|c|c|}
\hline \multicolumn{2}{|c|}{ Close Distance to seismic Source } & $>25 \mathrm{Km}(\mathrm{M}<6.5)$ \\
\hline \multicolumn{2}{|c|}{ Risk Category Of The Building } & III \\
\hline \multicolumn{2}{|c|}{ Seismic Design Category } & $\mathrm{B}$ \\
\hline Soil Profile Type & $\mathrm{S}_{\mathrm{C}}$ \\
\hline \multirow{2}{*}{ Spectral Response Acceleration } & $\mathrm{S}_{\mathrm{s}}$ & $0.4 \mathrm{~g}$ \\
\cline { 2 - 3 } & $\mathrm{S}_{1}$ & $0.1 \mathrm{~g}$ \\
\hline \multicolumn{2}{|c|}{ Soil Profile Type } & $\mathrm{C}$ \\
\hline Site Coefficient $F a$ & 1.2 \\
\hline Site Coefficient $F v$ & 1.7 \\
\hline Importance Factor, $\mathrm{I}_{\mathrm{p}}$ & 1.0 \\
\hline
\end{tabular}

The soil profile at the site consists of predominantly slightly hard marly marlstone massive rock. For redesign criteria and based on the seismic hazard of potentially active Dead Sea and Jordan Valley fault zone is an active seismic that is prone to earthquakes. Values of the seismic design parameters SS and S1 (spectral accelerations at 0.2 and 1.0 seconds, respectively, with 5\% damping) and probability $2 \%$ of time exposure in 50 years in accordance with the seismic map published by Israeli Standard SII 413-13 are presented in the Table 6. The encountered subsurface material is matching type $\mathrm{C}$ soil (bedrock) to represent the upper $30 \mathrm{~m}$ of the subsurface conditions.

\section{Conclusion and Recommendations}

Based on our inspection and on-site investigation results and engineering analysis the followings can be deduced:

1. In general, the existing condition of the building appeared in good condition and was structurally stable.

2. The internal plastering mortar layer at some locations was cracked, as well as stone -pointing mortar in the interior walls. Minor and very narrow flexural cracks appeared in open limited area.

3. According to the prevailing conditions of the building and our inspection results, the performance of the building and its serviceability could be improved by implementing an adequate rehabilitation and repair program. Repairs and rehabilitation works should include the followings:

1) The flexural crack appeared in the northern-east wall should be treated by re-pointing the stone joints. A cement -lime--sand mortar proportion should be selected with a compressive strength not exceeding the fieldstone. Type M mortar standard mix proportions specified by ASTM 270 may be used for re-pointing the stone-wall. The stone joints should be raked to a depth of 2 $1 / 2$ times of the joint thickness, but not less than a depth of $20 \mathrm{~mm}$. Mini grinder cutting disc may be used for raking the bed joints and avoiding damages to the adjacent stones.

2) Re-pointing the stone joints for the internal arch-stone. The old unsuitable and high strength pointing mortar should be removed and replaced with cement -lime-mortar of type $\mathrm{M}$ as specified by ASTM 270.

3) Where the stone joints are wide and the plastering layer is thick, fragments of clay tile may be used to avoid shrinkage effects and increase the adhesion in the groove pointing line. After cleaning the exposed stone surface and joints, two coats of plaster should be performed using cement, lime and sand mortar of proper proportion. Strips of a canvas or fabric-like material also may be used for thick coating of uneven wall surfaces.

4) Strengthening of the roof level in their plan throughout tying and anchoring of the walls with reinforced concrete slab and bond- beams at roof level. A reinforced concrete slab $10.0 \mathrm{~cm}$ thick with reinforcement bars $6 \varnothing 10$ each way should be placed over the roof slab. The reinforcement steel bars should be anchored into the supporting walls with an embedment length at least $20 \mathrm{~cm}$. Simultaneously with the slab being placed, perimeter bond-beams anchored to the stone walls are casted. The 
cross bond-beams should pass over the entire width of the longitudinal walls and the perimeter bond-beams should rest on a bearing distance not less than $200 \mathrm{~mm}$, therefore stones may be removed to allow casting of the bond beams together with the slab. Since the perimeter bond beams would only partially rest on the walls, a through steel bars dowels are needed to anchor the bond beams to the parapet stonewalls. Concrete mix of class B250 may be used for construction of the RC slab and bond-beams.

5) Reinstalling proper gutters at the roof. Proper direction of down spouts to move roof water away from the building. The downspouts should discharge away of the foundation. In order to minimize the effect of water against the foundation the downspouts should be piped a minimum of $30 \mathrm{~cm}$ away from the base of the foundation and building area and prevent moisture penetrating core of walls and the roof slab. It should be noted that it is necessary to use adequate waterproofing material to prevent water penetration and keep cores of all structural materials dry.
6) Before commencing the restoration works and constructional operations adequate supporting system should be installed. Also, during rehabilitation and construction works, no vibrating constructional equipment should be used and/or place accumulating heavy materials on the building slabs.

\section{Limitations}

1. This inspection report only deals with the structural evaluation according to the general condition of the building discernible. This inspection only covers the readily accessible areas of the building.

2. This report does not include the inspection and evaluation of items outside the scope of the requested inspection in this report.

\section{Acknowledgements}

All laboratory and field tests were carried out with the cooperation of Building Testing Centre under supervision of his manager Engineer A.N Shaheen.

\section{Appendix A Building Drawing Plans}

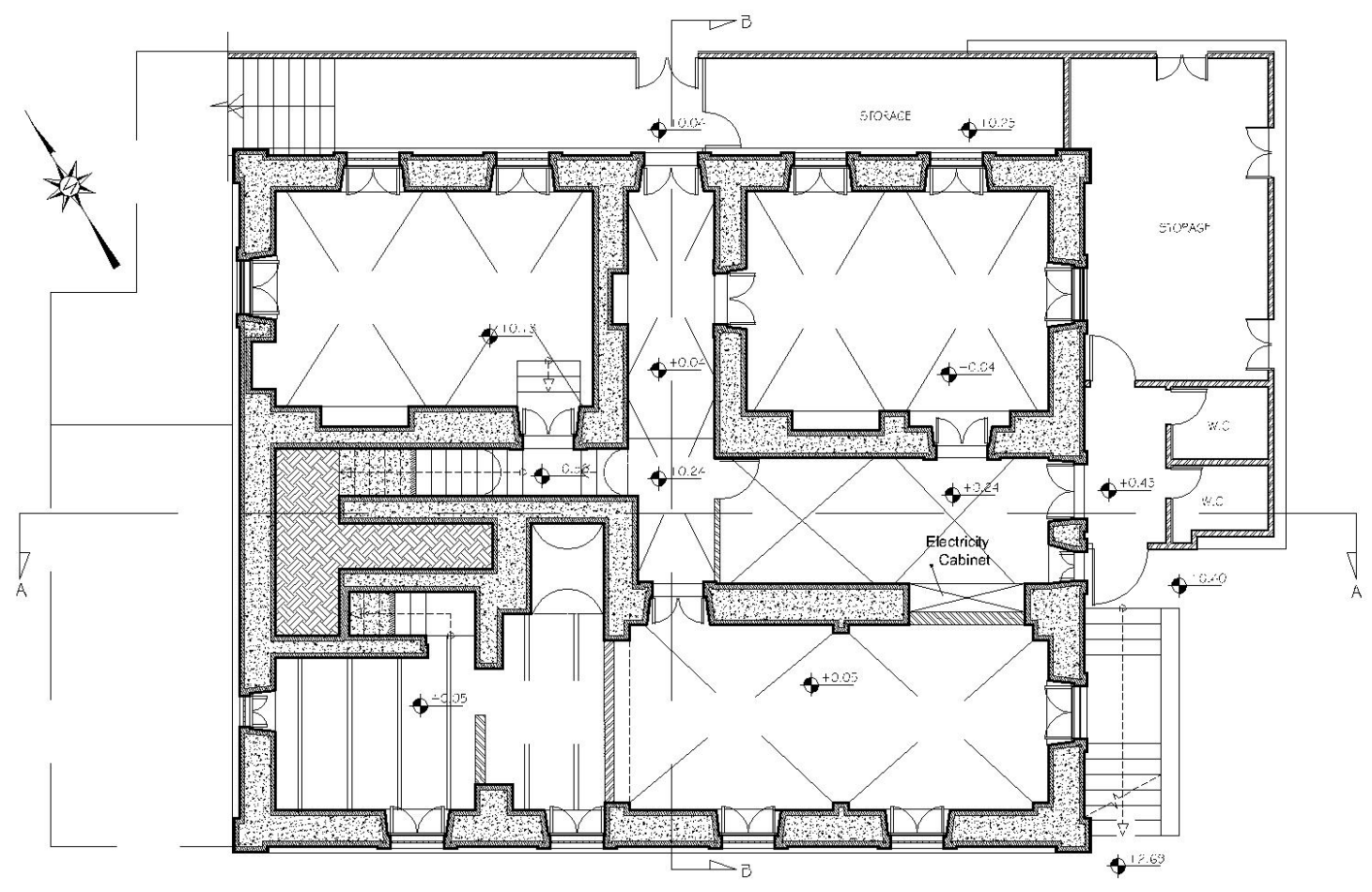

ground floor

Figure 1. Ground floor 


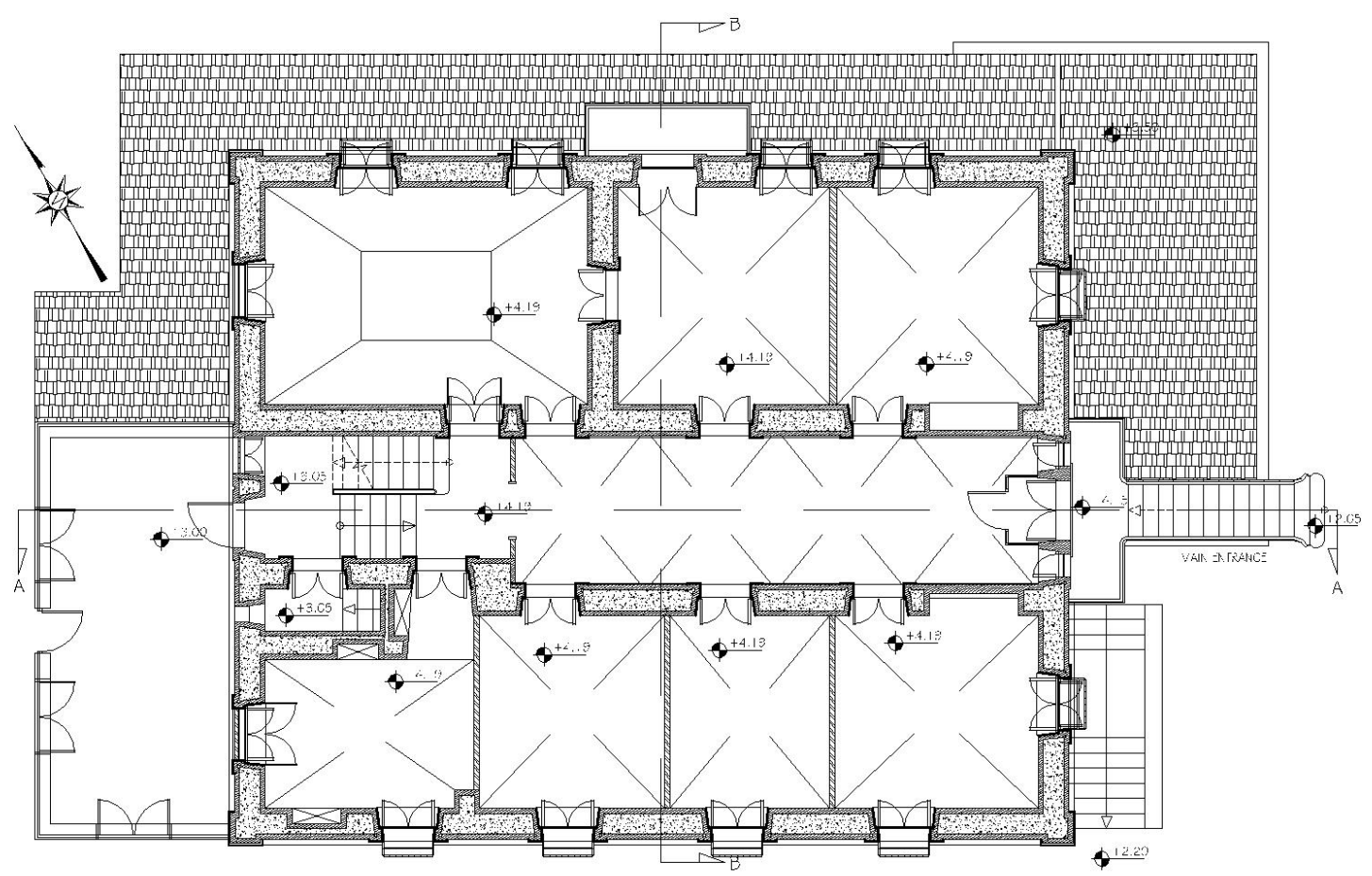

first floor

Figure 2. First floor

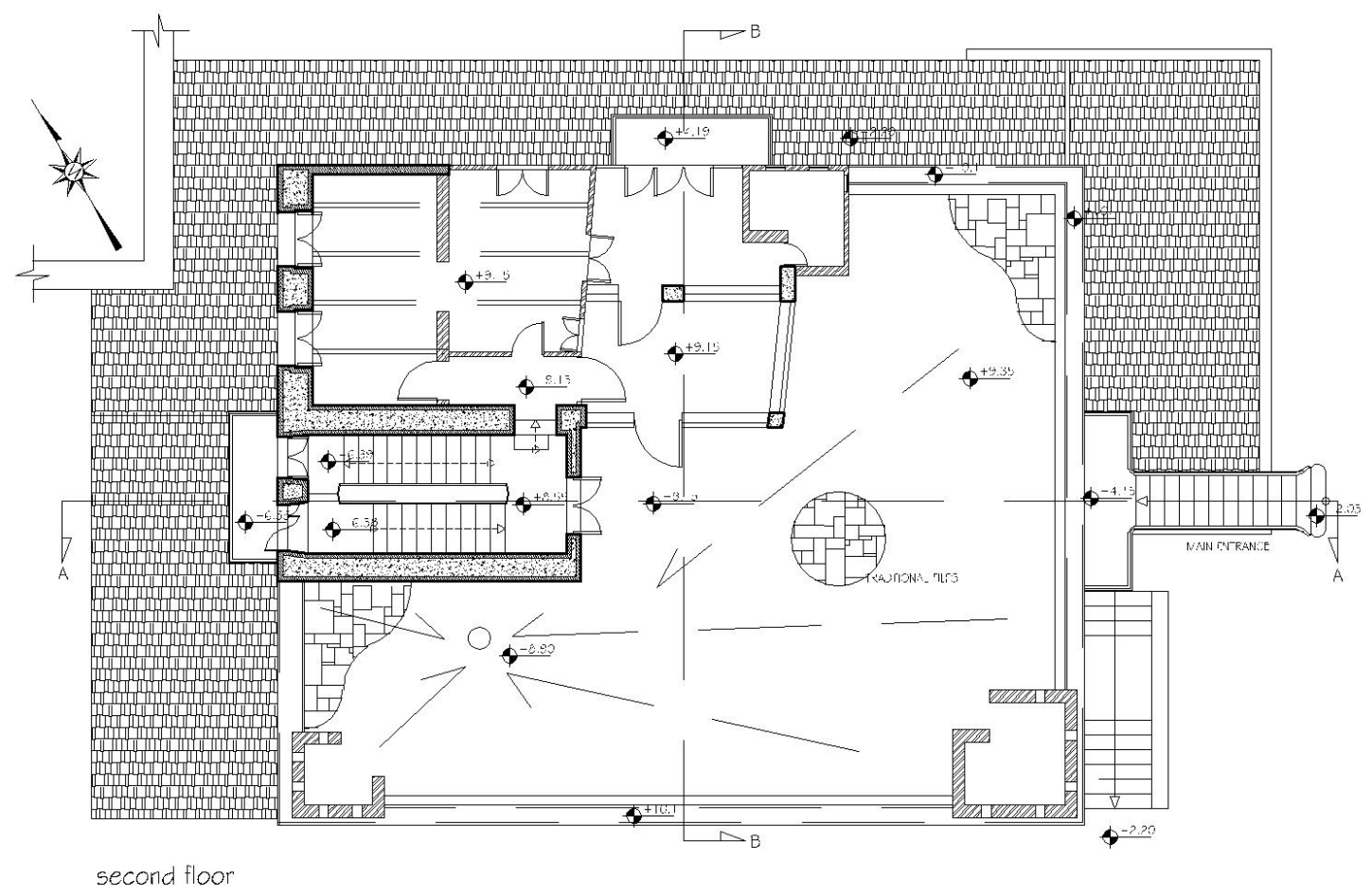

Figure 3. Roof floor 


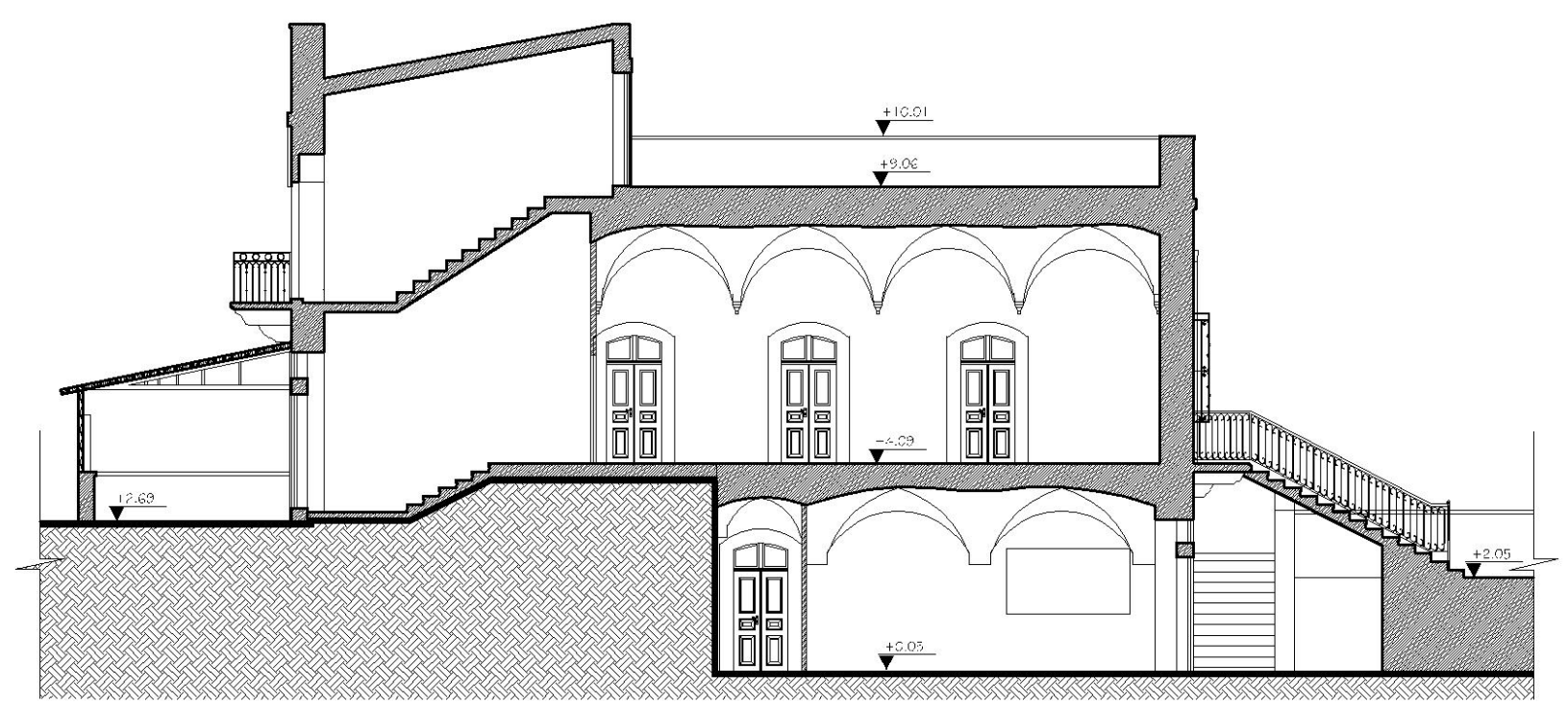

SECTION A-A - EXISTING

Figure 4. Section A-A

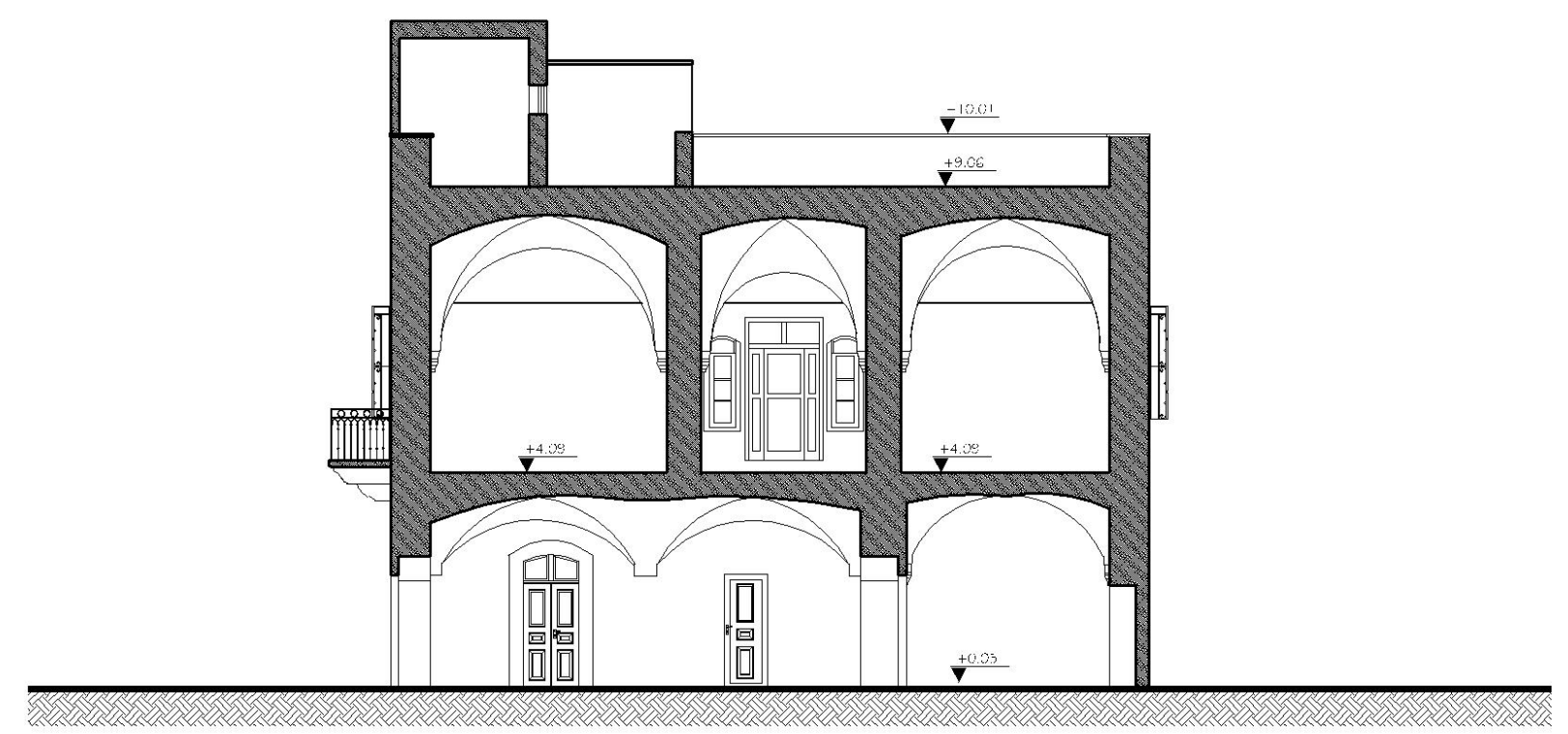

SECTION B-B - EXISTING

Figure 5. Section B-B

reports (1993): 401-401.

[3] Croci, G. "The Colosseum: safety evaluation and preliminary criteria of intervention." Structural Analysis of

\section{REFERENCES} Historical Constructions, Barcelona (1995).

[1] Chiarugi, A., M. Fanelli, and G. Giuseppetti. "Diagnosis and strengthening of the Brunelleschi Dome." IABSE REPORTS (1993): 441-441.

[2] Macchi, G., G. Ruggeri, M. Eusebio, and M. Moncecchi. "Structural assessment of the leaning tower of Pisa." IABSE

[4] Croci, G., and A. Viscovik. "Causes of failures of Colosseum over the centuries and evaluation of the safety levels." Public assembly structures. From antiquity to the present. IASS-Mimar Sinan University, Istanbul, Turkey (1993): 29-52. 
[5] Meli, R., and A. R. Sanchez-Ramirez. "Structural aspects of the rehabilitation of the Mexico City Cathedral." Structural analysis of historical constructions I, CIMNE, Barcelona, Spain (1995): 123-140.

[6] Mola, F., and R. Vitaliani. "Analysis, diagnosis and preservation of ancient monuments: The St. Mark's Basilica in Venice." Structural analysis of historical constructions I. CIMNE, Barcelona, Spain (1995): 166-188.

[7] Zienkiewicz, Olek C., Robert L. Taylor, and Jian Z. Zhu. The finite element method: its basis and fundamentals. Elsevier, 2005.

[8] Ngo, D_, and Alex C. Scordelis. "Finite element analysis of reinforced concrete beams." In Journal Proceedings, vol. 64, no. 3, pp. 152-163. 1967.

[9] Roca, P. "Considerations on the significance of history for the structural analysis of ancient constructions." Structural analysis of historical constructions 4 (2004): 63-73.

[10] ICOMOS/Iscarsah Committee. "Recommendations for the analysis, conservation and structural restoration of architectural heritage." www. icomos. org (2005) 